\title{
PULMONARY CAPILLARY BLOOD FLOW IN MAN 1,2
}

\author{
By G. DE J. LEE 3 AND A. B. DuBOIS \\ (From the Department of Physiology and Pharmacology, Graduate School of Medicine, \\ University of Pennsylvania, Philadelphia, Pa.)
}

(Submitted for publication March 2, 1955 ; accepted May 11, 1955)

Although it is obvious that the blood flow through the pulmonary artery is pulsatile, it is not so certain that it remains so within the pulmonary capillaries. On the contrary, the direct Fick method for measuring cardiac output expresses mean flow per unit time, and calculation of pulmonary arteriolar resistance tacitly assumes the existence of a non-pulsatile blood flow. Furthermore, it is not known whether the rate of gas diffusion from alveolus to capillary varies with the phase of the cardiac cycle.

The present communication describes a method for measuring instantaneous blood flow in the pulmonary capillary bed in man. A continuous recording of pressure within an airtight body plethysmograph is made before and after the inhalation of nitrous oxide. As the gas is absorbed by the blood entering the lung capillaries, the pressure within the body plethysmograph falls. This fall in pressure is proportional to the pulmonary capillary blood flow, and was found to vary according to the phase of the cardiac cycle.

\section{METHOD}

An airtight body plethysmograph of approximately 600 liters capacity, previously constructed for the measurement of alveolar pressure (1) was used (Figure 1).

The differential pressure between the plethysmograph chamber and an adjacent "compensatory" chamber was measured, using a Lilly capacitance manometer, Brush D.C. amplifier and recorder. This arrangement eliminated artefacts produced by extraneous sounds in the laboratory, alterations in room temperature and changes in ambient barometric pressure. The sensitivity of the recording system was $.04 \mathrm{~cm} . \mathrm{H}_{2} \mathrm{O}$ per $\mathrm{cm}$. deflection, and

1 These studies were aided in part by a contract between the Office of Naval Research, Department of the Navy, and the University of Pennsylvania, Graduate School of Medicine, NR 112-323.

2 Presented in preliminary form at the Fall Meetings of the American Physiological Society, 1954. DuBois, A. B., and Lee, G. de J., (Am. J. Physiol., In press).

${ }^{3}$ Holding a Travelling Fellowship from St. Thomas's Hospital, London. Present address : St. Thomas's Hospital, London, England. the response time was satisfactory up to a rate of 35 cycles per second. The pressure between the plethysmograph and compensatory chamber could be equalized by a valve, and the plethysmograph could be vented to the exterior by a solenoid operated valve in the wall of the chamber.

The subjects, who had been active in the laboratory, were permitted to sit for 5 to 15 minutes before entering the plethysmograph. During the test, they were required to breathe in a special way, and to turn valves; they were by no means basal. The subject sat in the closed plethysmograph with two 5-liter bags and two sampling tubes. His electrocardiograph (lead CF.4) was recorded simultaneously with the plethysmograph pressure, using a second Brush D.C. amplifier operating the remaining pen of the Brush recorder. Two minutes were allowed for temperature equilibration to occur, but in spite of this, some slight rise in pressure within the plethysmograph continued owing to continued heating of the contained air by the subject's body. To measure this and also R.Q. effects during the subsequent breathholding procedures a control record was first obtained. The subject twice exhaled almost to his residual capacity and then took a deep inspiration. After the second inspiration, he exhaled to resting lung volume and held his breath with the glottis open for a few seconds while simultaneous records of plethysmograph pressure and ECG were obtained. In addition to the pressure changes

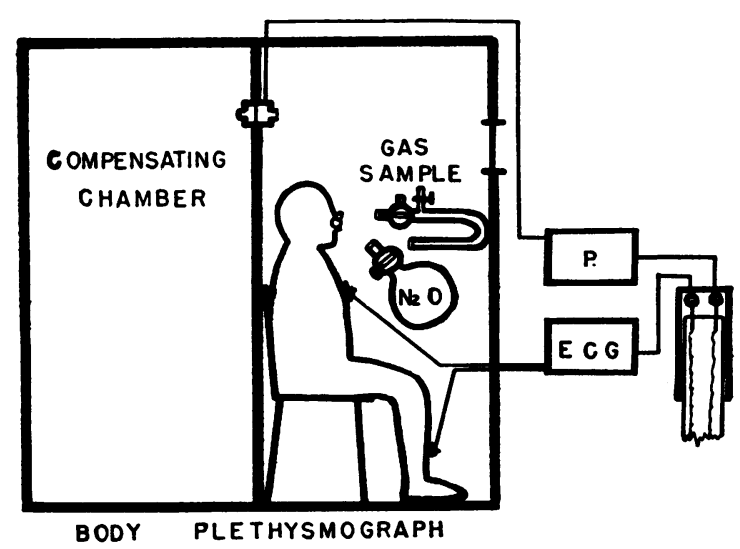

Fig. 1. Diagram of Body Plethysmograph, Manometer, and Electrocardiograph Recording System

For pictorial clarity, valves between the plethysmograph, compensating chamber, and the exterior are not shown. 


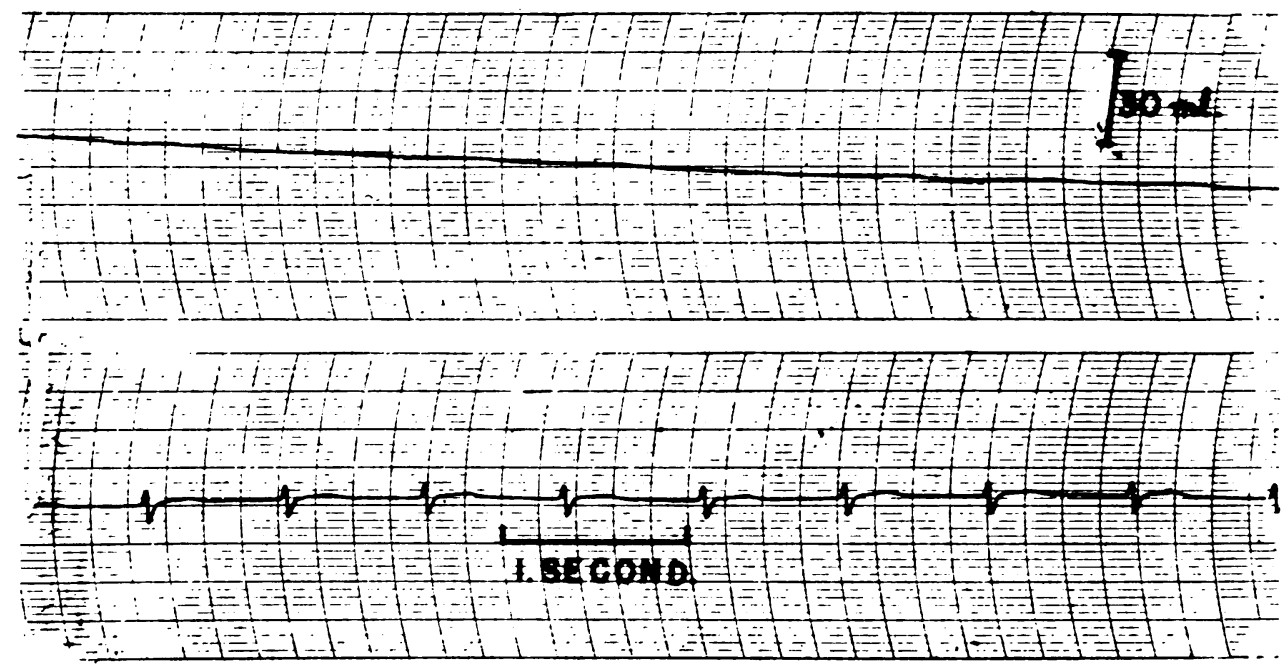

Fig. 2. Control Record during Breathholding after Air Inhalation

Plethysmograph pressure record (inverted) above, calibrated as a volume change. ECG shown below.

occurring from heating and R.Q. effects, small variations in pressure were seen to occur in association with the heart beat (Figure 2).

After a short period of normal breathing, the subject again exhaled almost to his residual volume and then took a deep inspiration from a 5-liter bag containing 100 per cent oxygen. This was done to raise the alveolar oxygen content so that when nitrous oxide was subsequently breathed, the resultant alveolar gas mixture would contain approximately the normal concentration of oxygen. Next, the subject again fully exhaled and took a maximal inspiration of 100 per cent nitrous oxide from a second 5-liter bag. He then exhaled through a Haldane gas sampling tube to resting lung volume and held his breath with the glottis open. The plethysmograph pressure fell in a characteristic fashion as the nitrous oxide was absorbed by the blood entering the lung capillaries (Figure 3 ). After 5 to 10 seconds breathholding the subject exhaled maximally through a second Haldane gas sampling tube.

The two expiratory samples were taken for subsequent analysis for nitrous oxide in a mass spectrometer. From these samples, the mean alveolar gas concentration during each cardiac cycle was calculated. The subject usually began to feel slightly 'intoxicated' some 15 to 20 seconds after inhaling the gas; this sensation disappeared rapidly after inhaling several breaths of air from the plethysmograph; it was more marked if oxygen was not inspired prior to the nitrous oxide inspiration.

The calculation of mean alveolar gas concentration from expired air samples assumes satisfactory distribution of the inspired gases within the lungs. All the subjects studied were healthy young adults. Under such circumstances it has been shown that the alveolar plateau recorded by a rapid gas analyzer can be extrapolated backward to the dead space $(2,3)$ and forward to the residual volume $(4,5)$. Since the mean concentration of alveolar gas is the mean of the integral of the product of concentration and volume over the entire range of lung volume, it is reasonable to assume that the mean alveolar concentration is represented as a point located at approximately mid expired volume on the alveolar plateau in a normal subject.

Expiration into a rapid gas analyzer showed that after a single breath of nitrous oxide, the alveolar gas concentration was approximately 58 per cent $\mathrm{N}_{2} \mathrm{O}$. However, if the breath was held at resting volume for varying intervals of time before exhaling into the analyzer, the alveolar concentration fell progressively at approximately 0.5 per cent $\mathrm{N}_{2} \mathrm{O}$ per second. After exercise, the rate of decline was considerably faster ( 0.7 to 1.8 per cent $\mathrm{N}_{2} \mathrm{O}$ per second).

The change in pressure in the plethysmograph was converted to volume change by calibrating with a small volume of air alternately injected and withdrawn, using a $30 \mathrm{ml}$. syringe or a diaphragm type pump. The calibrating volume under ambient conditions at $26^{\circ}$ to $28^{\circ}$ C., and 40 to 50 per cent saturated (unpublished measurements by Botelho) was converted to BTPS by an appropriate factor, assuming a barometric pressure of 760 $\mathrm{mm}$. $\mathrm{Hg}$. It produced a deflection of approximately 12 $\mathrm{mm}$. on the record.

Having completed the procedure under resting conditions, the whole procedure was repeated after half a minute of knee-bending exercises in the plethysmograph.

\section{Calculation of blood flow}

The solubility of nitrous oxide $\left(\mathrm{S}_{\mathrm{N}_{2} \mathrm{O}}\right)$ in whole blood is 47 vol. per $100 \mathrm{ml}$. blood per atmosphere at BTPS (6). Since the volume of $\mathrm{N}_{2} \mathrm{O}\left(\mathrm{V}_{\mathrm{N}_{2} \mathrm{O}}\right)$ which dissolves in the blood is proportional to the alveolar fraction of $\mathrm{N}_{2} \mathrm{O}$ 


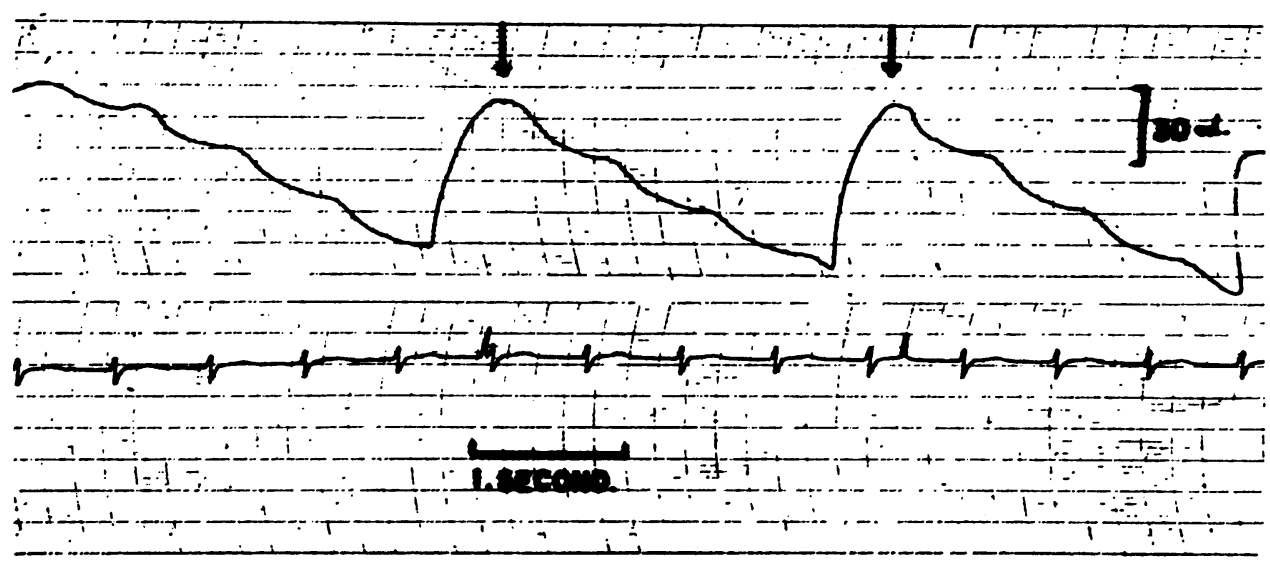

Fig. 3. Record Obtained during Breathholding after $\mathrm{N}_{2} \mathrm{O}$ Inhalation

Plethysmograph pressure record above, calibrated as a volume change. ECG shown below. Plethysmograph vented at arrows.

$\left(\mathrm{FAN}_{\mathrm{N}_{2} \mathrm{O}}\right)$, it is necessary to calculate the latter from the samples which have been analyzed, as the fraction of dry gas $\left(F_{N_{2} O}\right)$, by the formula: $F_{A_{N_{2} O}}=F_{N_{2} O} \cdot \frac{B-47}{760}$, where the symbols are standard (7).

The volume of gas absorbed in a given time $(t)$ is also proportional to the quantity of blood $(Q)$ equilibrated with the gas at that time. Combining terms

$$
\mathrm{V}_{\mathrm{N}_{2} \mathrm{O}}=\mathrm{S}_{\mathrm{N}_{2} \mathrm{O}} \cdot \mathrm{F}_{\mathrm{A}_{2} \mathrm{O}} \cdot \mathrm{Q} \text {. }
$$

Rearranging and differentiating with respect to time

$$
\dot{\mathbf{Q}}=\frac{\dot{\mathrm{V}}_{\mathrm{N}_{2} \mathrm{O}}}{\mathrm{S}_{\mathrm{N}_{2} \mathrm{O}} \cdot \mathrm{F}_{\mathrm{A}_{2} \mathrm{O}}},
$$

where $\dot{\mathbf{Q}}=$ cardiac output $\left.\begin{array}{l}\dot{\mathrm{V}}_{\mathrm{N}_{20}}=\text { rate of absorption } \\ \mathrm{S}_{\mathrm{N}_{20}}=\text { solubility in whole blood }\end{array}\right\}$ of nitrous oxide

all terms being expressed in liters per minute at BTPS.

Two separate methods for measuring the rate of gas absorption (V) were employed:

(a) Four consecutive cardiac cycles were measured for pressure deflection at 0.04 second intervals, commencing in time with each $\mathrm{R}$-wave of the ECG. The pressure changes during corresponding intervals of time in each cycle were then averaged to obtain a succession of mean values of $\nabla$ and so eliminate effects of random noise artefact.

The same was done for the control period, and the control values were subtracted from those obtained during the $\mathrm{N}_{2} \mathrm{O}$ period in order to eliminate the recurrent variations produced by mechanical gas compression with the heart beat, temperature, and R.Q. changes already mentioned.

(b) The output from the capacitance manometer amplifier recording the plethysmograph pressure (V) was led through a 'differentiating' circuit consisting of a capacitance $(C)$ and resistance $(R)$; the voltage across the resistance was measured by a Brush DC amplifier and recorder. The values of $C$ and $R$ were selected to give a time constant of 0.06 second. The output was approxi- mately proportional to the rate of change of pressure in the plethysmograph and hence proportional to the rate of blood flow (Figure 4).

It was considered that part of the pressure drop in the plethysmograph during nitrous oxide uptake might possibly be due to uptake in the lung tissues themselves, rather than by the blood. This possibility was therefore tested, using the trachea, heart and lungs of dogs, obtained immediately following the termination of other experiments in which the lungs had not been involved. These isolated lungs contained blood that was not flowing. The preparation was placed in a plethysmograph of approximately 25 liters capacity and inflation experiments were made which were identical with the procedure carried out by our subjects in the body plethysmograph. After the first second following inflation of the dog's lungs with 100 per cent nitrous oxide, only minor changes in plethysmograph pressure occurred:

Dog 1: $0.09 \mathrm{ml}$. per sec. $\mathrm{N}_{2} \mathrm{O}$ uptake. Weight of lungs: $176 \mathrm{gm}$.

Dog 2: $0.13 \mathrm{ml}$. per sec. $\mathrm{N}_{2} \mathrm{O}$ uptake. Weight of lungs: $155 \mathrm{gm}$.

Dog 3: $0.02 \mathrm{ml}$. per sec. $\mathrm{N}_{2} \mathrm{O}$ uptake. Weight of lungs : $174 \mathrm{gm}$. (Average: $0.08 \mathrm{ml}$. per sec. $\mathrm{N}_{2} \mathrm{O}$ uptake.)

Assuming that human lungs are approximately four times as heavy as those of the dog, then approximately $0.3 \mathrm{ml}$. $\mathrm{N}_{2} \mathrm{O}$ per sec. would be taken up, due to delayed equilibration. However, the uptake due to blood flow is approximately $30 \mathrm{ml}$. $\mathrm{N}_{2} \mathrm{O}$ per sec., so that the factor of delayed lung tissue equilibration is negligible in the present study on man.

Although $\mathrm{N}_{2} \mathrm{O}$ is an inert gas chemically, it seemed possible that it might be evoking a local vasodilator effect upon the lung vessels. This could have led to the production of a pulsatile blood flow within the lung capillaries not necessarily present in the normal state. To test this possibility, the pressures obtained via a catheter 

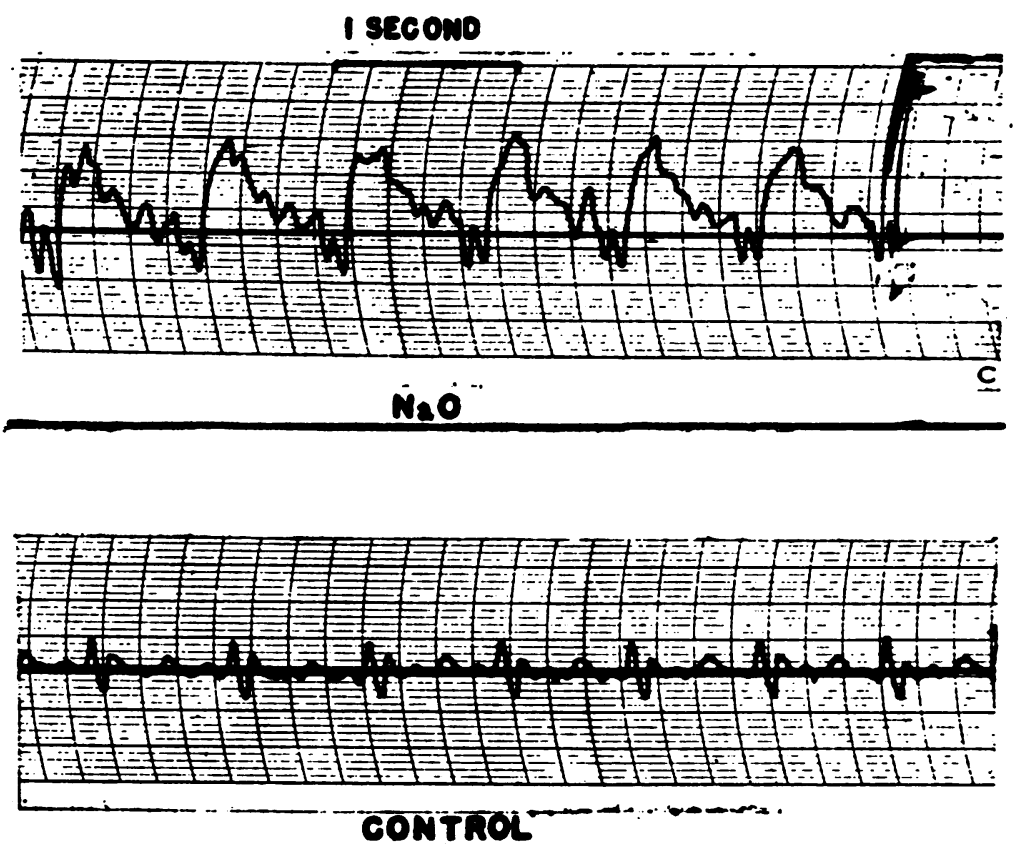

Fig. 4A. G. L. At Resting Lung Volume

Control record, on air, is below, and gas absorption record, on $\mathrm{N}_{2} \mathrm{O}$ is above.

wedged in the pulmonary vein of three open-chested dogs under light Nembutal@ anesthesia were studied. The animals alternately breathed room air and 50 per cent $\mathrm{N}_{2} \mathrm{O}$ in oxygen. No alteration in the pressure pulsations was obtained when the $\mathrm{N}_{2} \mathrm{O}$ mixture was breathed. This suggested that no change in the physical state of the vessels had occurred.

\section{RESULTS}

Instantaneous pulmonary capillary blood flow measurements with simultaneous electrocardio- graph records were obtained from five healthy young male subjects sitting at rest following laboratory activity and again immediately after moderate exercise. The results are shown graphically in Figures 5 and 6, where instantaneous flow rates expressed in liters per minute are shown in relation to the electrocardiographic events. In all instances the rate of pulmonary capillary blood flow is seen to vary markedly, being slowest shortly after the QRS complex of the ECG and most

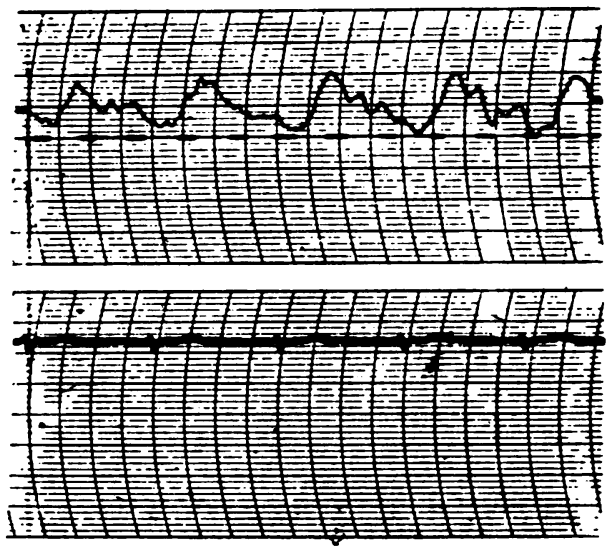

Fig. 4B. DuB in Expratory Position, Glottis Open

Control record, upper left, with ECG beneath. $\mathrm{N}_{2} \mathrm{O}$ record, upper right, with ECG below. 

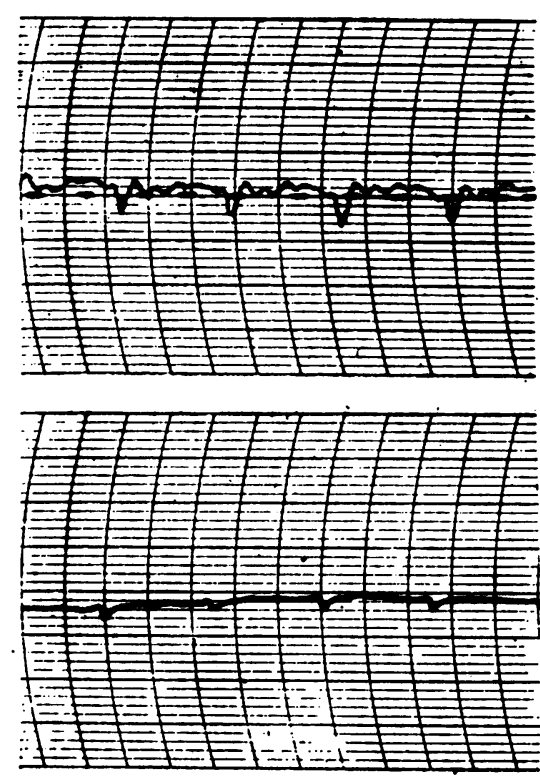
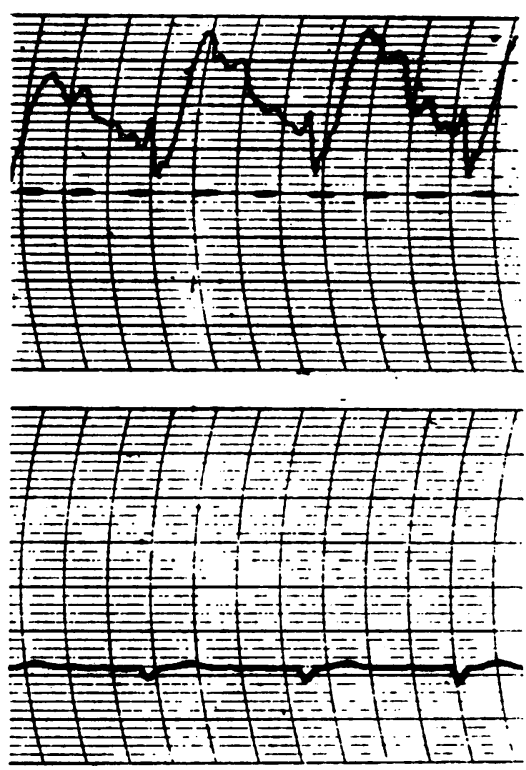

Fig. 4c. DuB after Exercise

Control record, upper left, with ECG underneath. $\mathrm{N}_{2} \mathrm{O}$ record, upper right, with ECG below.

\section{Fig. 4. "Differentiated" Plethysmograph Pressure Records}

rapid subsequent to onset of the $T$ wave. The closed circles in Figure 5 represent instantaneous flow rate measurements at each 0.04 second fol-

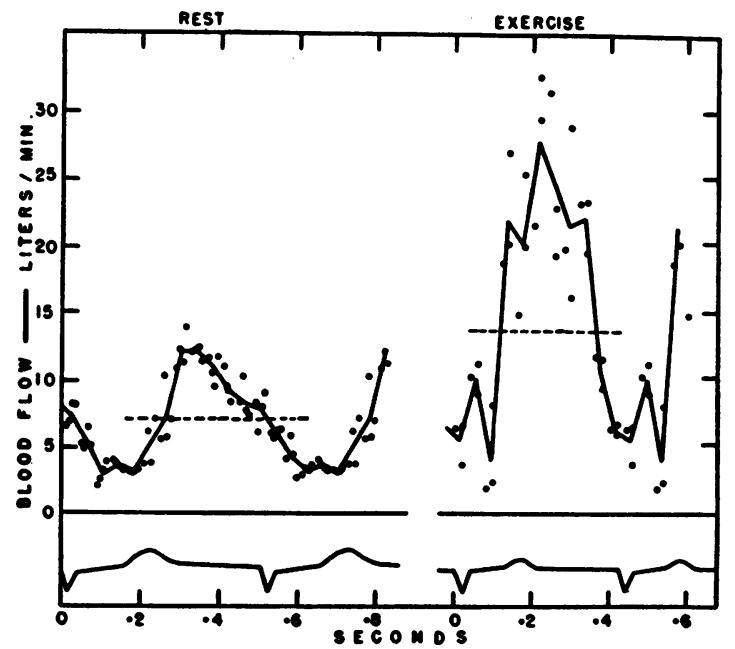

Fig. 5. Instantaneous Pulmonary Ca pillaty Blood Flow Rates at Rest and after Exercise Obtained from One Subject

Zero time arbitrarily taken as the $R$ wave of the ECG, shown below each flow curve. Closed circles represent instantaneous flow rates at every $0.04 \mathrm{sec}$. from four consecutive heart cycles. Solid line represents the average instantaneous flow rate obtained from those points. Dashed line represents mean cardiac output per minute. lowing the $\mathrm{R}$ wave (zero time) obtained from four consecutive heart cycles (see section on Calculation of blood flow). The solid line represents the average instantaneous flow rate of the four cycles. The dashed horizontal line represents the mean flow rate or mean cardiac output. In Figure 6, for the sake of pictorial clarity, only the line representing the average instantaneous flow rates of four cardiac cycles have been shown.

Sharp transient changes in flow rate occur in the regions at highest and lowest flow rate, as are shown in Figures 5 and 6 . Table I shows the maximal and minimal instantaneous flow rates that were obtained in each subject at rest and after exercise. The figures are approximate and have been obtained by visual inspection of Figures 5 and 6.

In all five subjects, both at rest and after exercise, the instantaneous pulmonary capillary blood flow rates were found to be pulsatile. They varied between 40 and $70 \mathrm{ml}$. per sec. (2.4 and $4.2 \mathrm{~L}$. per min.) during the period of minimal flow, and 203 and $426 \mathrm{ml}$. per sec. (12.2 and $25.6 \mathrm{~L}$. per min.) at maximal flow during rest. Following exercise, the minimal pulmonary capillary blood flow rates varied between 40 and $128 \mathrm{ml}$. per sec. ( 2.4 and $7.7 \mathrm{~L}$. per min.) and the maximal flow rates varied 


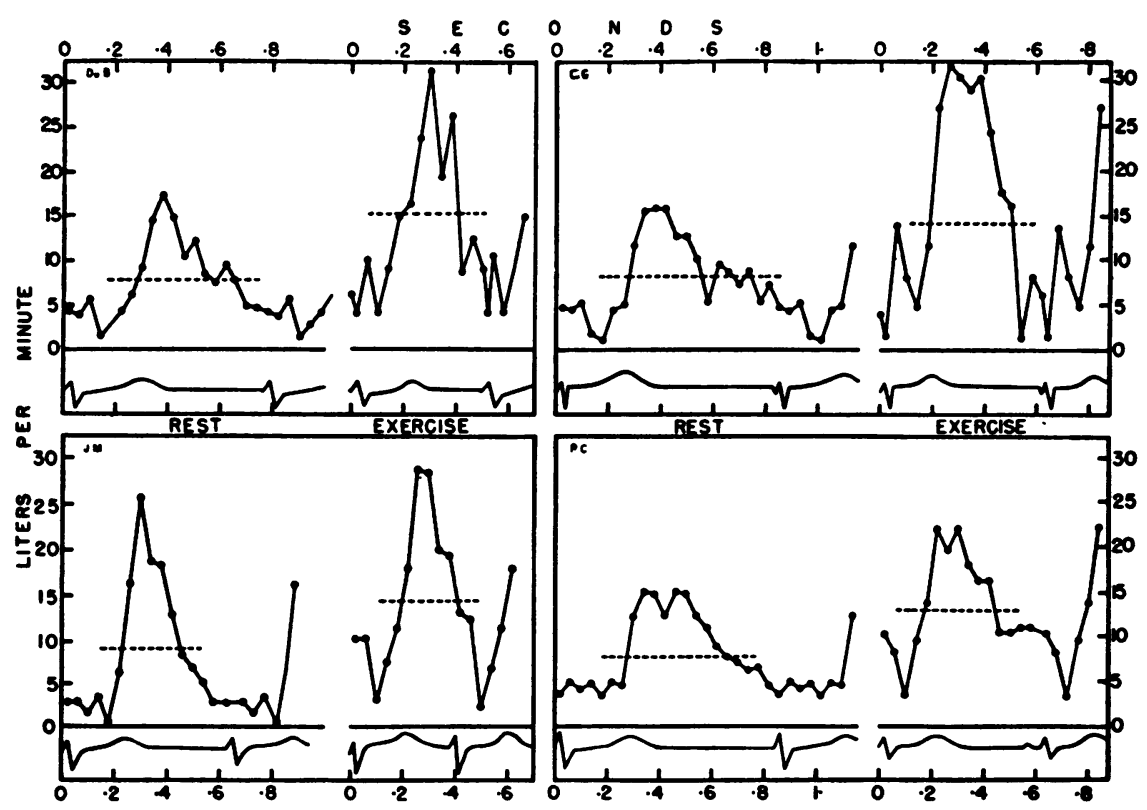

Fig. 6. The Average Instantaneous Pulmonary Capillary Flow Rate Curves Obtained from Four Consecutive Cardiac Cycles of Four Healthy Subjects at REST, AND AFTER EXERCISE

Zero time is arbitrarily taken as the $\mathrm{R}$ wave of the ECG, shown below each flow curve. The dashed line represents mean cardiac output per minute.

between 370 and $530 \mathrm{ml}$. per sec. (22.2 and 31.8 L. per min.).

In one individual (subject $M$ ) although the mean cardiac output per minute rose after exercise, the instantaneous flow rates per beat remained virtually unaltered. The rise in cardiac output was accomplished in this instance by change in cardiac frequency alone. In the other four subjects, both changes in cardiac frequency and increases in instantaneous pulmonary capillary blood flow rates (stroke output) were responsible for the rise in cardiac output. The ratio of maximal to minimal flow rates in the five subjects va- ried between 3.6 and 10.7 at rest, and 3.1 and 12.0 after exercise.

Stroke volume measurements can be made from the instantaneous flow curves (Figures 5 and 6), since the area of each curve represents pulmonary capillary blood flow per cardiac cycle. Hence, knowing the pulse rate, or from measurement of the mean slope of the plethysmograph pressure curve during $\mathrm{N}_{2} \mathrm{O}$ breathing (Figure 3 ), the mean cardiac output per minute can be obtained (Figure 7 and Table II).

The mean cardiac output in our resting, nonbasal subjects, was 7.9 L. per min. S.E. \pm .26

TABLE I

The maximal and minimal instantaneous pulmonary capillary blood flow rates compared with the mean cardiac output estimations in each of five healthy male subjects before and after moderate exercise

\begin{tabular}{|c|c|c|c|c|c|c|c|c|c|c|c|c|c|c|}
\hline \multirow{4}{*}{$\begin{array}{l}\text { Sub- } \\
\text { ject }\end{array}$} & \multicolumn{6}{|c|}{ Rest } & \multicolumn{6}{|c|}{ Exercise } & \multirow[b]{2}{*}{ Rest } & \multirow[b]{2}{*}{ Exercise } \\
\hline & \multirow{3}{*}{$\begin{array}{c}\text { Cardiac } \\
\text { fre- } \\
\text { quency } \\
\text { pulsel } \\
\text { min. }\end{array}$} & \multirow{2}{*}{\multicolumn{2}{|c|}{ Minimum }} & \multirow{2}{*}{\multicolumn{2}{|c|}{ Maximum }} & \multirow{3}{*}{$\frac{\text { Maximum }}{\text { Minimum }}$} & \multirow{3}{*}{$\begin{array}{c}\text { Cardiac } \\
\text { fre- } \\
\text { quency } \\
\text { pulsel } \\
\text { min. }\end{array}$} & \multirow{2}{*}{\multicolumn{2}{|c|}{ Minimum }} & \multirow{2}{*}{\multicolumn{2}{|c|}{ Maximum }} & \multirow{3}{*}{$\frac{\text { Maximum }}{\text { Minimum }}$} & & \\
\hline & & & & & & & & & & & & & \multirow{2}{*}{\multicolumn{2}{|c|}{$\begin{array}{c}\text { Mean cardiac } \\
\text { output } \\
\text { L./min. }\end{array}$}} \\
\hline & & ml. $/ \mathrm{sec}$. & L./min. & ml./sec. & L./min. & & & ml. $/ \mathrm{sec}$. & $L . / \min$. & ml./sec. & L./min. & & & \\
\hline $\begin{array}{l}\text { C. } \\
\text { DuB. } \\
\text { G. } \\
\text { M. } \\
\text { L. }\end{array}$ & $\begin{array}{r}72 \\
79 \\
72 \\
96 \\
118\end{array}$ & $\begin{array}{l}70 \\
43 \\
56 \\
40 \\
55\end{array}$ & $\begin{array}{l}4.2 \\
2.6 \\
3.4 \\
2.4 \\
3.3\end{array}$ & $\begin{array}{l}252 \\
290 \\
265 \\
426 \\
203\end{array}$ & $\begin{array}{l}15.1 \\
17.4 \\
15.9 \\
25.6 \\
12.2\end{array}$ & $\begin{array}{r}3.6 \\
6.7 \\
4.7 \\
10.7 \\
3.7\end{array}$ & $\begin{array}{r}97 \\
121 \\
97 \\
156 \\
141\end{array}$ & $\begin{array}{r}120 \\
128 \\
80 \\
40 \\
88\end{array}$ & $\begin{array}{l}7.2 \\
7.7 \\
4.8 \\
2.4 \\
5.3\end{array}$ & $\begin{array}{l}370 \\
526 \\
530 \\
480 \\
466\end{array}$ & $\begin{array}{l}22.2 \\
31.6 \\
31.8 \\
28.8 \\
28.0\end{array}$ & $\begin{array}{r}3.1 \\
4.1 \\
6.6 \\
12.0 \\
5.3\end{array}$ & $\begin{array}{l}7.8 \\
7.8 \\
8.2 \\
8.7 \\
7.1\end{array}$ & $\begin{array}{l}13.1 \\
15.4 \\
14.2 \\
14.2 \\
13.8\end{array}$ \\
\hline
\end{tabular}




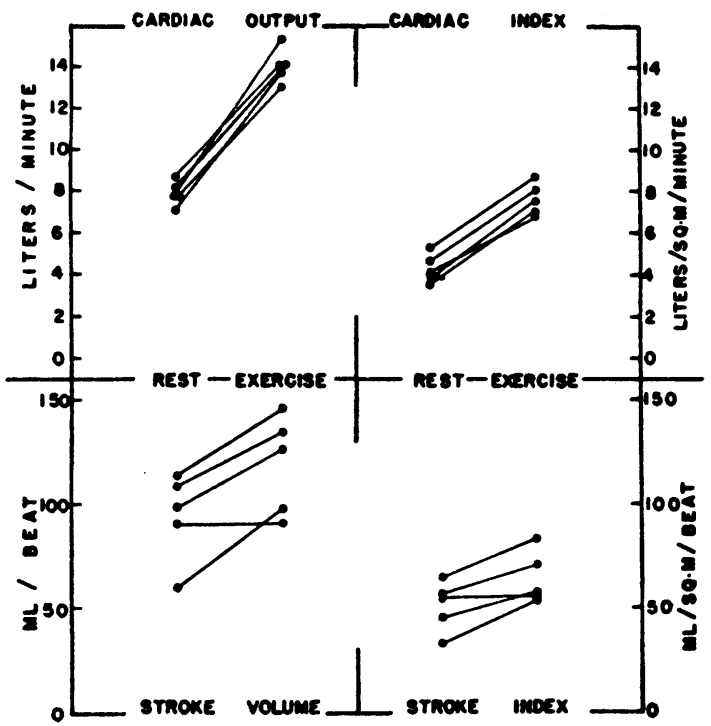

Fig. 7. Mean Cardiac Output and Stroke Volume Results Obtained from Five Healthy Male Subjects BEFORE AND AFTER EXERCISE

(4.3 L. per sq. meter per min.: S.E. \pm .32 ) ; and after exercise $14.1 \mathrm{~L}$. per min. S.E. \pm .37 (7.6 L. per sq. meter per min.: S.E. \pm .39).

No simultaneous estimates of cardiac output by other methods were carried out. However, the mean cardiac output by the direct Fick method or by the Hamilton dye injection technique on resting subjects appears to be less than the mean value on these subjects who were actively participating in the procedure.

\section{DISCUSSION}

The method here described for measuring pulmonary capillary blood flow incorporate some features of Krogh and Lindhard's single breath technique for measuring pulmonary blood flow in man, using nitrous oxide (8). It differs by using a differential manometric respirometer which allows instantaneous changes in gas uptake to be measured. It suffers from some of the disadvantages that previous indirect Fick methods for cardiac output measurement have had, whether using nitrous oxide, ethyl iodide, acetylene or carbon dioxide. These limitations result from re-circulation of blood during the gas breathing period, alterations of blood flow with each phase of respiration, and the necessity for obtaining a mean alveolar gas sample, which is only possible in subjects with reasonably uniform gas distribution in the lungs. However, accuracy of the alveolar gas sample is not so critical by this method. It also has the disadvantage, compared with the direct Fick method, that the subject must enter a closed chamber, and must be trained in the breathing procedure. Further, no associated data such as pressure measurements, or blood gas samples from various sites in the circulation, can be obtained as with catheter techniques. However it has the advantage of being the only method at present available for instantaneous blood flow in the pulmonary capillaries. Contrasted with it, the dye or isotope dilution methods for measuring cardiac output record the mean flow rate occurring over a period of several heart beats. The present technique allows instantaneous pulmonary capillary blood flow measurements to be made, and also makes possible measurement of the stroke volume of individual right ventricular contractions in man.

TABLE II

Cardiac output and stroke volume data obtained from five healthy male subjects at rest and after moderate exercise

\begin{tabular}{|c|c|c|c|c|c|c|c|c|c|c|}
\hline \multirow[b]{2}{*}{ Subject } & \multicolumn{5}{|c|}{ Rest } & \multicolumn{5}{|c|}{ Exercise } \\
\hline & $\begin{array}{c}\text { Cardiac } \\
\text { frequency } \\
\text { pulses } \\
\text { per mix. }\end{array}$ & $\begin{array}{l}\text { Cardiac } \\
\text { output } \\
\text { L./min. }\end{array}$ & $\begin{array}{c}\text { Cardiac } \\
\text { index } \\
L . / s q . m . / \\
\text { min. }\end{array}$ & $\begin{array}{l}\text { Stroke } \\
\text { volume } \\
\text { ml./beat }\end{array}$ & $\begin{array}{c}\text { Stroke } \\
\text { volume } \\
\text { index } \\
\text { ml./sq.m./ } \\
\text { beat }\end{array}$ & $\begin{array}{c}\text { Cardiac } \\
\text { frequency } \\
\text { pulses } \\
\text { per min. }\end{array}$ & $\begin{array}{l}\text { Cardiac } \\
\text { output } \\
\text { L./min. }\end{array}$ & $\begin{array}{c}\text { Cardiac } \\
\text { index } \\
\text { L./sq. m./ } \\
\text { min. }\end{array}$ & $\begin{array}{l}\text { Stroke } \\
\text { volume } \\
\text { ml./beat }\end{array}$ & $\begin{array}{c}\text { Stroke } \\
\text { volume } \\
\text { index } \\
\text { ml./sq. m./ } \\
\text { beat }\end{array}$ \\
\hline $\begin{array}{l}\text { C. } \\
\text { DuB. } \\
\text { G. } \\
\text { M. } \\
\text { L. } \\
\text { Mean }\end{array}$ & $\begin{array}{r}72 \\
79 \\
72 \\
96 \\
118 \\
87\end{array}$ & $\begin{array}{l}7.8 \\
7.8 \\
8.2 \\
8.7 \\
7.1 \\
7.9\end{array}$ & $\begin{array}{l}4.1 \\
3.5 \\
4.7 \\
5.3 \\
3.9 \\
4.3\end{array}$ & $\begin{array}{r}109 \\
99 \\
114 \\
91 \\
60 \\
95\end{array}$ & $\begin{array}{l}\mathbf{5 7} \\
45 \\
65 \\
56 \\
33 \\
51\end{array}$ & $\begin{array}{r}97 \\
121 \\
97 \\
156 \\
141 \\
122\end{array}$ & $\begin{array}{l}13.1 \\
15.4 \\
14.2 \\
14.2 \\
13.8 \\
14.1\end{array}$ & $\begin{array}{l}6.9 \\
7.0 \\
8.1 \\
8.7 \\
7.5 \\
7.6\end{array}$ & $\begin{array}{r}135 \\
127 \\
146 \\
91 \\
98 \\
119\end{array}$ & $\begin{array}{l}71 \\
58 \\
84 \\
56 \\
54 \\
65\end{array}$ \\
\hline S.D. & & .59 & .71 & 13.2 & 12.4 & & .83 & .87 & 5.0 & 3.6 \\
\hline S.E. & & .26 & .32 & 5.9 & 5.5 & & .37 & .39 & 2.2 & 1.6 \\
\hline
\end{tabular}


Two qualifications need to be made when interpreting flow data indicated by nitrous oxide uptake in the lungs. Firstly, since nitrous oxide diffuses with approximately the same speed as carbon dioxide, the equilibration between alveolar $\mathrm{N}_{2} \mathrm{O}$ and blood entering the pulmonary capillaries is theoretically complete long before the equilibration for oxygen, probably within the first $1 / 20$ th of the capillary length (6). The method therefore measures the rate of blood flow at the arteriolar end of the pulmonary capillary only, and gives no information about the blood flow at the venous end of the system. The second qualification concerns pulmonary ventilation-perfusion relationships. A region of lung receiving no ventilation, or presenting an impervious diffusion barrier, will absorb no $\mathrm{N}_{2} \mathrm{O}$ despite the presence of blood flow through that area. Such blood must be considered to be passing through a 'physiological shunt' and is not measured by the method.

The instantaneous pulmonary capillary blood flow curves obtained from the nitrous oxide uptake studies do not show a constant flow rate but are pulsatile, having the form and degree shown in the graphs of our five subjects (Figures 5 and 6). The blood flow tends to increase in pulsatility with exercise. Differential pressures between the pulmonary artery and "capillary" curves in man suggested the likelihood of pulsatile capillary flow (9).

Although the amplitude of pulsatility varied among the different subjects and under different physiological conditions, there were certain features to the curves that were consistent and reproducible. The pulmonary blood flow reached its slowest rate approximately 0.1 second after electrical systole and then rapidly accelerated during the period of the $T$ wave, to reach a peak blood flow approximately twice the mean blood flow. The rate of flow then diminished to reach a minimum rate, which was usually less than half the mean flow rate and approximately a fifth of peak flow rate. The instantaneous flow records show that these events do not occur in a smooth or sinusoidal wave form, but with abrupt angulations. Following peak flow there was usually a notch or sharp angulation in the curve; similarly, during the period of minimum flow there were sharp transient changes in the instantaneous flow rate. These sharp changes may be due to arte- facts resulting from mechanical compression by the heart of the gases within the lungs (10). On the other hand, since they appear so consistently it seems possible that they may represent real alterations in flow rate associated with the notch in the pulmonary arterial pressure record at the time of pulmonary valve closure in the first instance (11), and with left atrial systole in the second instance. These events would produce transient changes in pressure gradient across the capillary and hence affect capillary flow rates at these instants.

Since many calculations which use pulmonary blood flow as one of their parameters tacitly assume that the pulmonary capillary flow rate is constant, it is interesting to review these and consider whether errors may be introduced by the assumption of a steady flow. The following sections of the discussion are speculative rather than experimental.

\section{Gas exchange}

The concepts of ventilation and perfusion, and the ratio $\dot{V} / \dot{Q}$ presume a steady ventilation and steady blood flow for convenience of calculation. Calculation of the variation of alveolar gas tensions during the respiratory cycle (12) shows that under normal conditions and during the steady state it is satisfactory to assume a steady ventilation. The exceptions to this are that the alveolar gas concentrations during a single respiratory cycle and during sudden changes in ventilatory rate do not fluctuate along the same line as the $\dot{V} / \dot{Q}$ ratio. A superficial examination of the effects of pulsatile blood flow will reveal much the same state of affairs. Exchange of oxygen and carbon dioxide between the capillary blood and alveolar gas should mostly take place during the rapid phase of blood flow (systole) and very little during the slow phase (diastole). This intermittent exchange would result in a halting type of progression round the loop describing fluctuations of $\mathrm{PO}_{2}$ and $\mathrm{PCO}_{2}$ on the $\mathrm{O}_{2}-\mathrm{CO}_{2}$ diagram during a single respiratory cycle (12). Since the respiratory loop itself causes little effect on the $\dot{V} / \dot{Q}$ ratio, intermittent progression round the loop should have little additional effect. In other words, under most circumstances it is satisfactory to assume a constant pulmonary blood flow as far 
as the $\dot{V} / \dot{Q}$ ratio is concerned. Again, the exception occurs when rapid changes in alveolar gas concentration are measured. Under such circumstances, instead of a smooth and continuous change in gas concentration as previously supposed, one would expect to find changes occurring in an intermittent fashion. It is of interest that such an intermittency of concentration change has already been noted by Bartels, Severinghaus, Forster, Briscoe, and Bates from continuous analysis of the expired air for $\mathrm{O}_{2}, \mathrm{CO}_{2}$, and $\mathrm{N}_{2}$, using a rapid gas analyzer (13).

Analysis of the alveolar-arterial oxygen gradient is based on the $\dot{V} / \dot{Q}$ ratios discussed above. With the presence of a pulsatile capillary blood flow it is possible to conceive of a situation where an A-a gradient, not present in a steady system, could exist. This would exist where the diffusing capacity for oxygen were such that the systolic spurts of blood flow would pass through the capillaries too rapidly to become saturated and where the diastolic pauses could not make up for the systolic rush. Here saturation would be reached at the mean flow rate, and not improved by a slow diastolic flow rate. Such a situation would require that various elements of the stroke output stay in the capillary system unequal lengths of time. This has not been determined experimentally as far as we know.

\section{Hemodynamics}

There is no theoretical reason to challenge the direct Fick method for cardiac output measurement during the steady state on the grounds of pulsatile blood flow, but it is interesting to note that the mean blood flow actually exists during only two brief instants of the cardiac cycle during the rise and fall of the instantaneous flow curve. To test the method further, simultaneous direct Fick and plethysmograph measurements of cardiac output need to be made. In the present investigation, the phase of respiration at which the breath was held was seen to influence the stroke volume, which was greatest during inspiration and least during the expiratory phase. In preliminary experiments, the Valsalva maneuver was studied and was found to be associated with a marked increase in stroke volume during the period of the hypertensive overshoot. This is not in agreement with the findings of others who reported a fall in cardiac output during the overshoot period, using the dye technique (14). The stroke volume events associated with the Valsalva maneuver are a gross example of the unsteady state. Calculations were made from constantly timed blood samples, with the result that a disproportionately large concentration of dye was collected during the overshoot period when the stroke volume was large. With the plethysmograph method, nitrous oxide uptake is entirely dependent on flow. The importance of obtaining constant volume samples rather than constant time samples in any modification of the Fick principle for cardiac output measurement is thus well demonstrated in situations where the unsteady state exists $(15,16)$.

The combination of the elasticity of the arteries and the resistance of the arterioles is capable of converting the pulsatile output of the left ventricle into a constant capillary blood flow in the systemic vascular system. However, the findings here reported regarding pulmonary capillary flow indicate that, although the elasticity of the pulmonary arteries maintains a certain diastolic capillary flow, the combination of this elasticity and the pulmonary arteriolar resistance is not sufficient to induce a constant capillary blood flow. With techniques now available it should be possible, from simultaneous pressure flow data, to separate the factors of elasticity, resistance, and inertia in the pulmonary arterial system. In the absence of such information, it seems likely that the ratio of mean pressure to mean flow commonly used to express "pulmonary arteriolar resistance" will include components of elasticity and inertia. We believe that it would be more logical to calculate the "pulmonary impedance" until the elasticity and inertia factors are computable.

In a pulsatile system it is difficult to conceive of a single value for pulmonary capillary blood volume during all phases of the blood flow, unless the pulmonary capillary inflow exactly matches outflow in time and degree. If this were the case, the oxygen diffusing capacity would tend to decrease with exercise (pulsatile variation of the A-a gradient), the reverse in fact being the case. It would seem more likely that in such a system the pulmonary capillary volume would be capable of increasing to accommodate sharp increases in flow, with the result that the transit time through the 
alveolar capillary would remain approximately constant. Exercise would then be associated with an increase in oxygen diffusing capacity, as has been shown to be the case (17-19). The change in pulmonary capillary volume could occur by passive dilatation of already patent vessels as flow increased. Alternatively, the capillary volume could increase by the opening up of previously closed capillaries as flow rate increased and the pressure within the vessels exceeded a certain critical value. Regulation of pulmonary capillary volume by such a critical opening mechanism is an attractive hypothesis $(20,21)$. Maintenance of a constant pulmonary artery pressure in the face of large and rapid flow changes would become explicable on a physical basis, and the apparent lack of neurogenic control of pulmonary vascular tone would become less perplexing. In addition, opening of fresh vessels at high flow rates would allow both capillary transit time and the diameter of each open capillary to remain constant, with the result that conditions of gas diffusion would remain optimal at all flow rates. Microscopic observation showed opening or closing of lung capillaries in the anesthetized cat (22) and also various types of blood flow, sometimes pulsatile, sometimes steady.

In summary, conditions of pulsatile flow may be expected to produce certain hemodynamic and gas exchange effects which would be absent if the pulmonary capillary blood flow were constant as has sometimes previously been assumed.

\section{SUMMARY}

1. A method is described for measuring instantaneous pulmonary capillary blood flow in man.

The subject sat in a body plethysmograph and the plethysmograph pressure was continuously recorded during breathholding after inspiration of nitrous oxide. The plethysmograph pressure fell as the gas was absorbed by the blood entering the pulmonary capillaries. The rate of uptake of nitrous oxide so measured was proportional to the pulmonary capillary blood flow.

2. Observations were made on five healthy male subjects before and after moderate exercise. Pulmonary capillary blood flow was not steady but pulsatile.

Following electrical systole, there was a rapid acceleration of flow to a rate about twice the mean cardiac output, followed by a more gradual decline to low rates of flow. The cycle was repeated with each heart beat.

3. The possible effects on gas exchange and upon the hemodynamics of the pulmonary circulation are discussed.

\section{ACKNOWLEDGMENTS}

We wish to thank Dr. Robert E. Forster for help and advice in using the mass spectrometer for nitrous oxide analysis; also Dr. Julius H. Comroe, Jr., and Dr. Stella Y. Botelho who designed and built the plethysmograph; and Dr. Carl C. Gruhzit for help during the animal experiments.

\section{REFERENCES}

1. DuBois, A. B., Botelho, S. Y., and Comroe, J. H., Jr., Resistance to airflow through the tracheobronchial tree as measured by means of a body plethysmograph. J. Clin. Invest., 1954, 33, 929.

2. Fowler, W. S., Lung function studies. II. The respiratory dead space. Am. J. Physiol., 1948, 154, 405.

3. Fowler, W. S., and Forster, R. E., II. A method for producing uniform distribution of inspired gas. Federation Proc., 1952, 11, 48.

4. Lilly, J. C., Mixing of gases within respiratory system with a new type nitrogen meter. Am. J. Physiol., 1950, 161, 342.

5. Lanphier, E. H., Determination of residual volume and residual volume/total capacity ratio by single breath technics. J. Applied Physiol., 1953, 5, 361.

6. Kety, S. S., The theory and applications of the exchange of inert gas at the lungs and tissues. Pharm. Rev., 1951, 3, 1.

7. Pappenheimer, J., et al., Standardization of definitions and symbols in respiratory physiology. Federation Proc., 1950, 9, 602.

8. Krogh, A., and Lindhard, J., Measurements of the blood flow through the lungs of man. Skandinav. Arch. f. Physiol., 1912, 27, 100.

9. Cournand, A., Some aspects of the pulmonary circulation in normal man and in chronic cardiopulmonary diseases. The fourth Walter Wile Hamburger Memorial Lecture, Institute of Medicine, Chicago. Circulation, 1950, 2, 641.

10. Blair, H. A., and Wedd, A. M., The action of cardiac ejection on venous return. Am. J. Physiol., 1946, $145,528$.

11. Bloomfield, R. A., Lauson, H. D., Cournand, A., Breed, E. S., and Richards, D. W., Jr., Recording of right heart pressures in normal subjects and in patients with chronic pulmonary disease and various types of cardio-circulatory disease. J. Clin. Invest., 1946, 25, 639. 
12. DuBois, A. B., Alveolar $\mathrm{CO}_{2}$ and $\mathrm{O}_{2}$ during breath holding, expiration, and inspiration. J. Applied Physiol., 1952, 5, 1.

13. Bartels, J., Severinghaus, J. W., Forster, R. E., Briscoe, W. A., and Bates, D. V., The respiratory dead space measured by single breath analysis of oxygen, carbon dioxide, nitrogen or helium. J. Clin. Invest., 1954, 33, 41.

14. McIntosh, H. D., Burnum, J. F., Hickam, J. B., and Warren, J. V., Circulatory changes produced by the Valsalva maneuver in normal subjects, patients with mitral stenosis, and autonomic nervous system alterations. Circulation, 1954, 9, 511.

15. Visscher, M. B., and Johnson, J. A., The Fick principle: Analysis of potential errors in its conventional application. J. Applied Physiol., 1953, 5, 635.

16. Stow, R. W., Systematic errors in flow determinations by the Fick method. Minnesota Med., 1954, 37, 30.

17. Krogh, M., The diffusion of gases through the lungs of man. J. Physiol., 1915, 49, 271.
18. Lilienthal, J. L., Jr., Riley, R. L., Proemmel, D. D., and Franke, R. E., An experimental analysis in man of the oxygen pressure gradient from alveolar air to arterial blood during rest and exercise at sea level and at altitude. Am. J. Physiol., 1946, 147, 199.

19. Riley, R. L., Shepard, R. H., Cohn, J. E., Carroll, D. G., and Armstrong, B. W., Maximal diffusing capacity of the lungs. J. Applied Physiol., 1954, 6, 573.

20. Burton, A. C., On the physical equilibrium of small blood vessels. Am. J. Physiol., 1951, 164, 319.

21. Nichol, J., Girling, F., Jerrard, W., Claxton, E. B., and Burton, A. C., Fundamental instability of the small blood vessels and critical closing pressures in vascular beds. Am. J. Physiol., 1951, 164, 330.

22. Wearn, J. T., Ernstene, A. C., Bromer, A. W., Barr, J. S., German, W. J., and Zschiesche, L. J., Normal behavior of pulmonary blood vessels with observations on intermittence of flow of blood in arterioles and capillaries. Am. J. Physiol., 1934, 109, 236. 